\title{
Study on the Properties of the organosilicon-acrylic resin/LDHs nanocomposite
}

\author{
Wei zhao ${ }^{\text {a }}$, Yuhong $\mathrm{Li}^{\mathrm{b}}$ \\ Department of Chemistry,Xianyang Normal University, Xianyang 712000,China

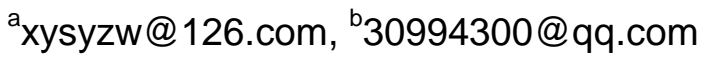

Keywords: organosilicon-acrylic resin; emulsion polymerization; namocomposite; Mg-Al-AA-LDHs

Abstract. The organosilicon-acrylic resin/LDHs nanocomposite was prepared from acrylate, organosilicon, Mg-Al-AA-LDHs, as well as emulsifier etc with emulsion polymerization methods. The samples prepared were characterized by optical, thermal and gas barrier capabilities testing, Results show the samples were nanocomposion, which Tg was disappear, and changed the nature of the acrylic resin of the "hot sticky cold brittle" defects fundamentally; The degradation temperature of organosilicon-acrylic resin/LDH was $470^{\circ} \mathrm{C}$ when $\mathrm{LDH}$ content is $3 \%, 77^{\circ} \mathrm{C}$ higher than pure organosilicon-acrylic resin. With the increase of mass fraction of namo-AA-LDHs, the light transmittance increased, the fog degree reduced, the oxygen transmittance reduced and the water vapor transmittance slightly increased.The namocomposites had excellent thermal properties, outstanding optical and gas barrier properties.

\section{Introduction}

Layered double hydroxides is a kind of anionic layered inorganic functional materials, Which unit layer is formed by $\mathrm{MgO}_{6}$ octahedral public edge, $\mathrm{Mg}^{2+}$ located in a layer can be replaced by similar radius $\mathrm{Al}^{3+}$ within a certain scope, making the layer with $\mathrm{Mg}^{2+}, \mathrm{Al}^{3+}, \mathrm{OH}^{-}$is positively charged layer, interlayer exchangeable anion $\mathrm{CO}_{3}{ }^{2-}$ with positive charge balance layer board, making the structure is electrically neutral. There are some water molecules between the layers. Compared with the layered silicate, $\mathrm{LDH}$ is rarely used in the preparation of polymer/layered compounds nanometer composite material. However, LDH is easier to adjust the physical and chemical properties than layered silicate ${ }^{[1]}$. LDH nanocomposites have structural, size, performance advantage ${ }^{[2-3]}$ and its structure can be designed and regulation.Using intercalated modified $\mathrm{LDH}$, introducing functional organic molecular polymer preparation of polymer/LDH nanocomposites ${ }^{[4]}$, which is from the nanometer or molecular level to design of polymer composite material structure, given composite materials with outstanding mechanical, thermal properties, excellent weather resistance, flame retardant, wear-resisting infrared absorption performance and the advantages of non-toxic, non-polluting, and has a broad application prospect. In the present work we report organosilicon modified acrylic resin/ LDH nanocomposites were synthesized by emulsion polymerization reaction and studied its performance.

\section{Experiment}

\section{Materials}

Butyl acrylate (BA), acrylic acid, methyl methacrylate (MMA) and methyl acrylate(MA) were supplied by Xi'an Zhenxing Chemical Plant, OP-10, Sodium dodecyl benzene sulfonate (DBS), $\mathrm{K}_{2} \mathrm{~S}_{2} \mathrm{O}_{7}, \mathrm{Mg}\left(\mathrm{NO}_{3}\right)_{2}, \mathrm{Al}_{2}\left(\mathrm{NO}_{3}\right)_{3}$ were odtained from Shanghai Chemical Reagent Corporation. organosilicon with vinyl group and nano-AA-LDH nanocomposites were synthesized in our own lab. All the above commercial chemicals were analytically pure grade.

\section{Preparation of samples}

The pre-emulsified course is taken by mixed a given use level of water, OP-10 and DBS composite emulsifying agent at $70^{\circ} \mathrm{C} 30 \mathrm{~min}$. Then organosilicon modified acrylic resin/ $\mathrm{MgAl} \mathrm{LDH}$ 
composite emulsion were synthesized through the seed emulsion polymerization by dropping the monomer of acrylic resin, the self-made organosilicon and the organo modified nano-AA-LDH. Emulsion samples were placed in the ptfe mould, natural moisture to evaporate at room temperature, after waiting for film, drying 6 hours under $60{ }^{\circ} \mathrm{C}$, zero defect film was formed

\section{Measurements}

Differential scanning calorimetry (DSC) patterns were collected on $50 \sim 100^{\circ} \mathrm{C}$ and Heating rate $10^{\circ} \mathrm{C} / \mathrm{min}$ at DSC200PC from Germany NETZSCH. The Thermo-gravimetric analysis (TG) was analyzed by Differential thermal balance from Beijing, the Gas barrier properties were tested by the oxygen transmittance according to GB 1037-88; the vapor transmittance Through steam performance by GB1038-70.

\section{Results and discussion}

\section{the thermal properties of the organosilicon-acrylic resin / LDHs nanocomposite DSC analysis}

The product prepared by copolymerization and blending were made into film, DSC analysis was carried out on the thin film.

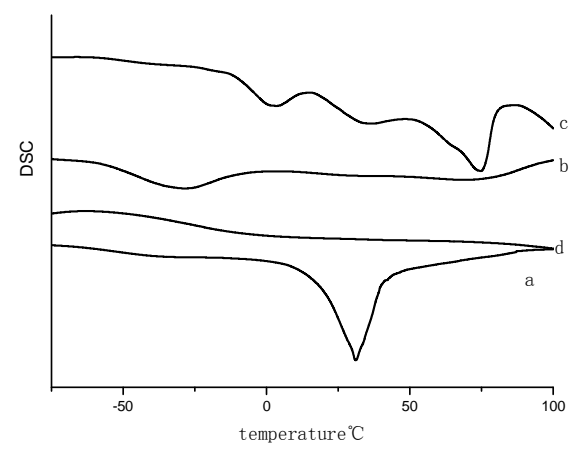

Fig.1 DSC of samples

( $a$ acrylic resin b organosilicon-acrylic resin c organosilicon-acrylic resin /LDH comixed nanocomposite d organosilicon-acrylic resin /AA-LDHs nanocomposite )

From figure 1 you can see that glass transition temperature of acrylic resin was $18^{\circ} \mathrm{C}$, the glass transition temperature of organosilicon-acrylic resin was $26^{\circ} \mathrm{C}$, the organosilicon-acrylic resin /LDHs blend nanocomposite was $0^{\circ} \mathrm{C}$ and $18^{\circ} \mathrm{C}$, and the glass transition temperature of organosilicon-acrylic resin/LDHs nanocomposite with in-situ polymerization was disappear, whch was not a micro phase separation system. Beacause the introduction of organic silicon and composition of nanomaterials, the low temperature resistance of acrylic resin had been improved obviously. To analyze its reasons: (1) the main chain of the organic siloxane rotation was almost free and very smooth. Glass transition temperature of polydimethylsiloxane was $-123^{\circ} \mathrm{C}$, which is the lowest in all of the polymer. the introduction of organic silicone could make its glass transition temperature decreased. (2) the organic silicone modified acrylic resin /LDH blend nanocomposites film had two glass transition temperature, because they were micro phase separation system.(3) because system did not exist the micro phase separation,the glass transition temperature of organosilicon-acrylic resin / LDHs nanocomposite with in-situ polymerization was basic disappear at -80-- $100^{\circ} \mathrm{C}$. And acrylic resin molecular chain had entered into LDH layers that form the nano intercalation composite material, so that the molecular chain were suffer from the bondage of LDH, leading to the chain segment motion resistance increases, activities becoming difficult, and the activity of the composite materials in the polymer chain was lower than that of pure polymer, so glass transition was made a slightly higher temperature ${ }^{[5]}$. disappear glass transition temperatures was proof that acrylic column brace hydrotalcite and copolymerization of acrylic resin improved the pure acrylic resin emulsion "hot sticky cold short" defects. 


\section{TG analysis}

The thermal degradation of organosilicon-acrylic resin and organosilicon-acrylic resin /LDH were mainly occurs between $300 \sim 550^{\circ} \mathrm{C}$. After $300^{\circ} \mathrm{C}$, organosilicon-acrylic resin was degradate rapidly, while organosilicon-acrylic/LDH was degradate only at a very slow rate before $410{ }^{\circ} \mathrm{C}$ and weight loss within $10 \%$, the weightlessness was due to dehydration of the LDH layers and volatile of the thermal oxidation products of resin.At the weightlessness of $50 \%$, compare to temperature of degradation of samples that the organosilicon-acrylic was $393^{\circ} \mathrm{C} .1 \% \mathrm{LDH}, 3 \% \mathrm{LDH}$ of the degradation of silicon acrylic resin/LDH were $424^{\circ} \mathrm{C}$ and $470^{\circ} \mathrm{C}$ respectively, higher than the pure organosilicon-acrylic resin respectively $31^{\circ} \mathrm{C}$ and $77^{\circ} \mathrm{C}$. so organosilicon-acrylic /LDH nanocomposites thermal stability than pure organosilicon-acrylic resin had greatly improved, this can be attributed to LDH layers in organosilicon-acrylic were dispersion in molecular level and the reinforcement effect of carbon in degradation process.

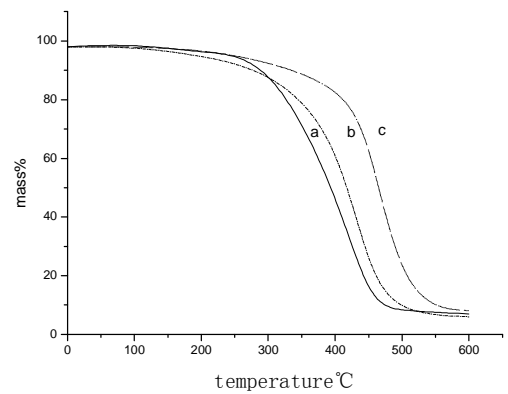

Fig.2 TG of samples

(a organosilicon-acrylic resin b $1 \% \mathrm{LDH}$ c $3 \% \mathrm{LDH}$ )

the optical properties of the organosilicon-acrylic resin / LDHs nanocomposite

Tab.1 optical properties organosilicon-acrylic resin /_LDHs nanocomposite

\begin{tabular}{clllll}
\hline Nano-AA-LDH/\% & 0 & 1 & 2 & 3 & 4 \\
\hline transmittance $/ \%$ & 87.3 & 90.6 & 91.4 & 93.5 & 90.1 \\
haze $/ \%$ & 26.5 & 22.0 & 20.8 & 19.4 & 22.9 \\
\hline
\end{tabular}

From table 1 you can see that with the increase of mass fraction of namo-AA-LDHs, the light transmittance of membrane increases, the fog degree reduced, and at its peak at about $3 \%$. It was mainly because nanoparticles had the role of heterogeneous nucleation on the matrix resin, increasing the crystallization rate and crystallinity of the resin, the crystalline would grain small size and uniform, which reduced the refraction of light; on the other hand, the refractive index of nano-AA-LDH was similar small to acrylic resin $(1.50,1.51)$, the light loss was small though the film, therefore, increase film pervious to light quality, while fog degree reduced. When it was over $3 \%$ due to reunite effect the increase of the nanoparticles, making its loss of heterogeneous nucleation, acrylic resin crystallization rate fell, the grain size increases, thus increasing the refraction of light, light transmittance and haze increased ${ }^{[6]}$. 


\section{the gas barrier properties of the organosilicon-acrylic resin / LDHs nanocomposite Effect of the content of namo-AA-LDHs on the oxygen transmittance}

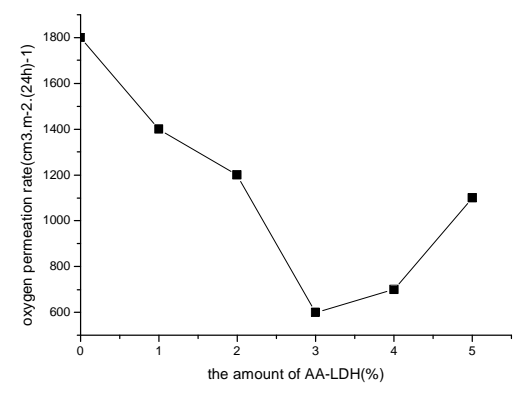

Fig.3 Effect of oxygen transmittance on the the amount of namo-AA-LDHs

From figure 3 you can see that the oxygen transmittance of film reduced with the increase of amount of nano-AA-LDH and when the mass fraction of nano-AA - LDH was more than 3\% oxygen transmittance was significantly increased. Beacause AA - LDH layers were uniformly distributed in the organosilicon-acrylic resin when the dosage of nano-AA-LDH was small, the oxygen through the migration path greatly extended, which reduces the oxygen transmittance, the oxygen transmittance increases when the dosage increased to a certain degree (greater than $3 \%$ ), this is due to nanometer particle collision probability increase under the action of external force, which could make the happening of the nanoparticles reunion, particle size increase, layered structure was destroyed.

\section{Effect of the content of MgAl LDH on the vapor transmittance}

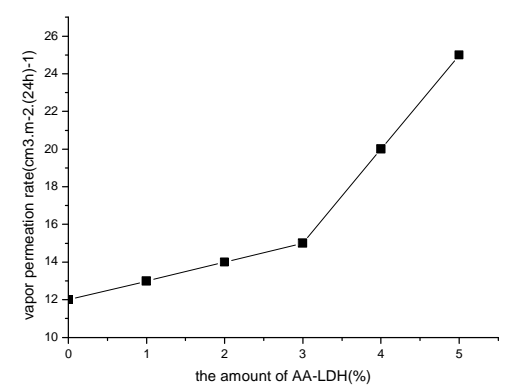

Fig.4 Effect of vapour transmittance on the the amount of namo-AA-LDHs

From figure 4 you can see that the vapor transmittance of film increased slightly with the increase of amount of nano-AA-LDH. This is mainly because the $\mathrm{OH}^{-}, \mathrm{COO}^{-}$on the $\mathrm{LDH}$ had strong hydrophilicity. The more the amount of namo-AA-LDH, the more hydrophilic group on the film surface, the greater the water imbibition, and vice versa. Beacause organosilicon-acrylic resin was strong hydrophobic polymer and had a strong barrier for vapor, preventing the internal nano-LDH to absorb vapor, the vapor transmittance of film increased less when the amount of was no more than $3 \%$.

\section{Conclusions}

(1) the organosilicon-acrylic resin / LDHs nanocomposite was prepared by in situ polymerization with acrylic monomers, silicone acrylic polymers and pillar of Acrylic acid.

(2) The samples prepared were characterized by optical , thermal and gas barrier capabilities testing, Results show the samples is nanocomposion, which Tg is disappear, and change the nature of the acrylic resin of the " hot sticky cold brittle" defects fundamentally, given composite materials with outstanding optical, thermal properties, and gas barrier properties. 


\section{Acknowledgements}

This work was financially supported by the Shaanxi Natural Science Foundation (2013JM2016), the Science Foundation of Shanxi Province Educational Office (2013JK0642) .

\section{Rerences}

[1] Hirokazu Nakayama,Natsuko Wada. Journal of Pharmaceutics. Vol. 269 (2004), p. 469

[2] Zhao Dong,Bai Zhimin. Journal of the Chinese Ceramic Society. Vol. 40 (2012), p. 769

[3] Manuela Zubitur, Agurtzane Mugica ,Javier Areizaga . Colloid Polym Sci , Vol. 288 (2010), p. 809

[4] Yan Yuan, Wenfang Shi. Progress in Organic Coatings, Vol. 69 (2013), p. 92

[5] Toshiyuki Tanaka, Shunsuke Nishimoto, Yoshikazu Kameshima. Journal of Solid State Chemistry, Vol. 183(2014), p. 479

[6]M Herrero, S Marinez-Gallegos, F M Labajos. Journal of Solid State Chemistry ,Vol. 183 (2011), p. 2862 